\title{
TOWARD BETTER DESIGN-RELATED DECISION MAKING: A PROPOSAL OF AN ADVANCED OODA LOOP
}

\author{
Vettorello, Mattia; Eisenbart, Boris; Ranscombe, Charlie \\ Swinburne University of Technology
}

\begin{abstract}
To be successful in innovation, organisations need to be dynamically adaptable to novel situations to avoid getting 'left behind'. Yet, they face vast uncertainties stemming from unforeseeable technological shifts or future user and market behaviour, making strategic decision-making on innovation an extremely difficult task. Decision-makers thus increasingly try to control or shape the future, rather than foresee it. This includes thinking ahead and generating potential pathways that will make an innovation viable. This captures the essence of designerly ways of thinking in reasoning toward 'what might be'. Extant literature has been reviewed that discusses alternative strategies how this future-oriented thinking can be applied to become better at selecting novel ideas for development. We observe parallels between divergent thinking, abductive reasoning, analogising and lateral thinking suggested by different authors in this process. The paper continues to propose how these key mechanisms can be embedded within an existing framework for decision-making under uncertainty, the 'OODA Loop', which has seen increasing uptake in such decision-making scenarios.
\end{abstract}

Keywords: Strategic Decision Making, Future Oriented Thinking, Decision making, Uncertainty, Innovation

Contact:

Vettorello, Mattia

Swinburne University of Technology

Dept. Architectural and Industrial Design

Australia

vettorello.mattia@gmail.com

Cite this article: Vettorello, M., Eisenbart, B., Ranscombe, C. (2019) 'Toward Better Design-Related Decision Making: A Proposal of an Advanced OODA Loop', in Proceedings of the 22nd International Conference on Engineering Design (ICED19), Delft, The Netherlands, 5-8 August 2019. DOI:10.1017/dsi.2019.245 


\section{INTRODUCTION}

As the world becomes more globalised and competitive, (engineering) design innovation related to products, services or a combination of these, becomes a key driver for organisations and individuals to diversify and remain competitive. Likewise, however, uncertainties related to technological advancement or future user and market behaviour make strategic decision-making on innovation increasingly difficult. Specifically, this refers to decision-making under extreme uncertainties, where a novel innovation is coupled with entry to a completely new market, which the company is not familiar with. In response, companies seek ways and skills that will help them increase their dynamic capabilities, i.e. the ability to flexibly adapt to a new situation, explore new areas, and generate novel, desirable solutions. This is a way of thinking quickly, recognising changes and act upon them shaping future-orientated innovations and creating a competitive advantage (Kelly, 2005; Brown, 2009; Cross, 2011; Dorst, 2011; Kleinsmann et al., 2017). Increasingly, they turn to the realm of design in this search, following seminal work by Landoni et al. (2016), for instance, who show how design-driven innovation can facilitate an organisation's competitiveness in strategic areas. This is because designerly ways of thinking, reasoning and acting can be instrumental in linking 'what might be' with 'what is now' (see Dong et al., 2015). However, adopting a designerly mindset and ways of thinking is hard to achieve, owing to the fact that it mainly builds on tacit knowledge (Teece \& Pisano, 1994). Thus, there is an acute need to support decision makers in the process of selecting innovation and research shows that under uncertainty it is extremely challenging to make a suitable decision, since crucial analytical information is missing. Shane (2009) states that success in new market is impossible to predefine and the veracity of the decision is very low. For this reason, many companies are now trying to control the future rather than predicting it (Sarasvathy, 2001). This increasing acknowledgement of design to support decision-making directly can be seen in Ensici et al. (2008), who highlight the gradual increase in components and activities related to decision-making by design, from the 1970s to today. Focus, therein, increasingly shifts to emphasise the second half of the decision-making process, which combines generation of knowledge, alternatives and synthetisation of criteria, ideas and solutions.

By definition, innovation is based on novel ideas, often utterly different from existing ideas and therefore bound to carry many uncertainties (Csikszentmihalyi, 1999). Mckenzie et al. (2011, p. 411) define decision-making as a knowledge-intensity activity characterised by "novelty, complexity, openendedness and lack of structure" (see also Mitzberg, 1976; Mason \& Mitroff, 1981 in Kotina et al., 2017). Whether extreme uncertainty stems from parameters and developments that cannot be foreseen with good probability, or whether the decision itself is hindered by unknowns about the state of relevant internal and external factors (Walker et al., 2013), making a decision in such a scenario is hampered by ambiguity of information and possible outcomes. Huang and Pearce (2015) describe extreme uncertainty as characterised by unknowable unknowns (see also Diebold et al., 2010). By extension, this also means that it is not always clear which tasks, tools or knowledge could help to increase certainty for making 'good' decisions and select the best option out of a given set (Assink, 2006). Thus, selecting innovation successfully is becoming more and more complex and challenging. Consequently, scholars like Teece (2007) propose that the capability to anticipate and seize novel opportunities, transforming resources and capabilities flexibly to keep in step with market dynamics, will become a more and more vital organisational capability.

Ensici et al. (2008) and Berg (2016) show empirically that in the decision-making phase key capabilities are not necessarily limited to convergent thinking (like passing judgement and selecting) but in combining such convergent thinking with divergent thinking and related cognitive strategies like abductive reasoning, analogising and creative thought in idea generation. Berg (2016) in particular was able to show how stronger divergent capabilities are instrumental in making 'good' decision on innovation. This finding is supported by Dong, Garbuio \& Lovallo (2016), De Bono (1970) and Baron (2006) whose research informs that the use of abductive reasoning, lateral thinking or analogising, respectively, is directly correlated with better decision-making performance in strategic decisions on innovation. In other words: instead of focusing solely on the idea as it is presented at the point of decision-making and any evidence for why it may become a success, it is suggested to think towards what it could become, then construe strategies to make this innovation a viable future.

There is little research on the topic of how divergent thinking should be applied by decision makers in a deliberate manner as most of the related research is still quite fundamental. This paper aims to better understand the mechanisms behind divergent thinking strategies in decision-making and operationalise 
them in an implementable framework. In relation to utilisation, we also discuss a framework that is becoming more and more prevalent in decision-making under uncertainty in the business context, i.e. the so-called OODA Loop. The following section introduces the OODA Loop, a decision-making framework that can 'contextualise' our research. Then, Section 3 presents a review of key literature which outlines key mechanisms. Section 4 proposes an advanced OODA Loop discussing the integration of mechanisms. Conclusions and further work are presented in Section 5.

\section{OODA LOOP}

The OODA Loop (see Figure 1) is relevant to this study because it offers a framework which can act as a vehicle to carry out designerly thinking mechanisms. The acronym stays for: Observe, Orient, Decide and Act - it will be further explained below - and it was originally developed by John Boyd in the latter half of the $20^{\text {th }}$ Century for military purpose (air-to-air combat). Essentially, it represents a decision-making framework that now has been found to see increasing application in the context of decision-making under uncertainty in businesses.

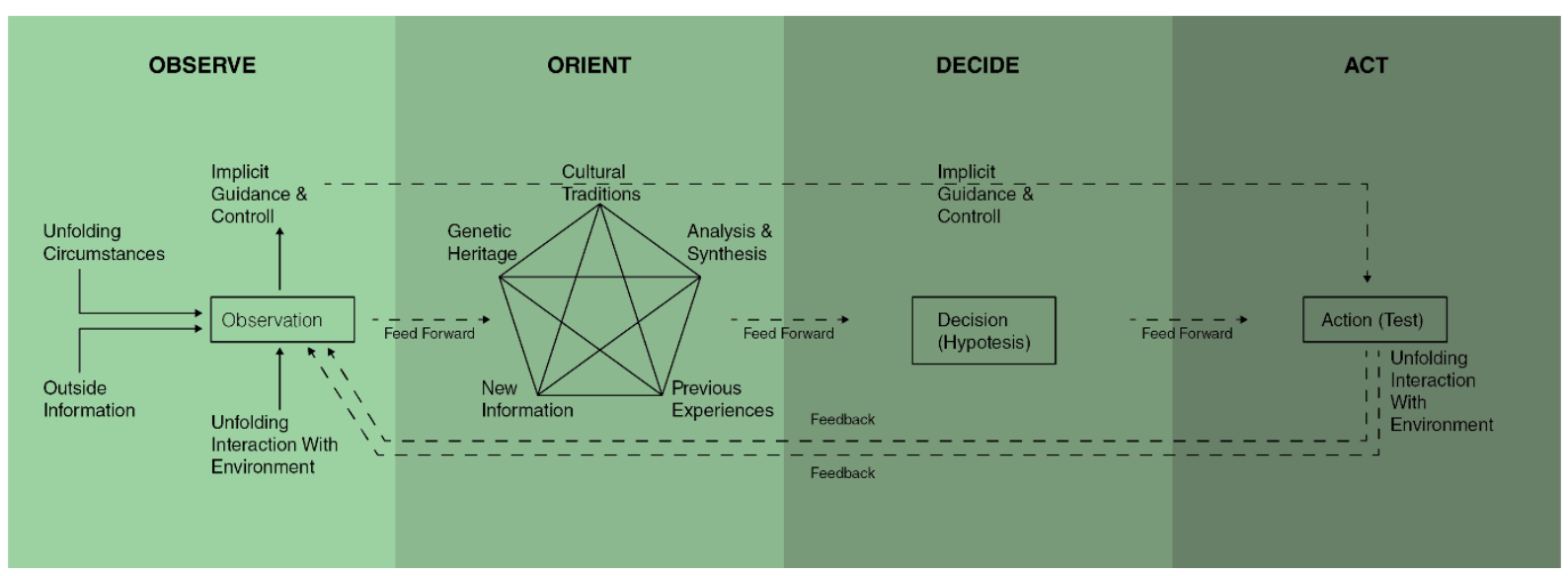

Figure 1. OODA loop by John Boyd (in Enck, 2012)

In the original conceptualisation, the pilot observes the variable and surrounding, orients the aircraft to an advantageous position in relation to his opponent. Then they quickly and sharply decide the following course of actions in order to engage with the adversary. This phase contains the rapid generation of hypothesis - in a given context and under changing conditions - of the consequences of any action undertaken and to generate alternatives of action and potential outcomes. Thus, there is not only a mere selection process, but an effective production of hypotheses and their forecast of possible future consequences that will have impact on the decision-making of the pilot, i.e. to adjust accordingly if something will not work as desired. The OODA Loop is now more and more permeating into the business world. We see similarities on how the company inspects the encompassing and outer layers of a problem to Orient its capability to discover unmet needs or market opportunities. The insights gained from collecting data benefits the hypothesis generation phase and subsequent convergence to eventually, act rapidly upon that decision. In between all four steps there are iteration cycles leading to making decisions with a very fast pace. In the military environment, a second can make a difference to prevailing in battle; equally, in innovation companies must decide quickly to look at an idea more thoroughly or waive on the opportunity early (Bonchek \& Fussell, 2013).

In this research, we seek to complement the findings from fundamental research on divergent thinking and their underlying cognitive strategies with the hypothesising phase of the OODA Loop. Thereby, the framework would cohesively combine convergent and divergent thinking to guide decision-making under uncertainty which is directly applicable to strategic decision-making on innovation. In the decision phase, there are overlaps with divergent thinking, abductive reasoning, lateral thinking and analogising. Both have the attribute of generating alternatives in a given context and changing conditions which require high adaptability and capability to change accordingly. This is further supported by another attribute like the generation of hypotheses of future outcomes following a particular decision.

Taking each step of the OODA Loop individually, we define Observation as to understand the context, what's possible, what's not, in other words the viability of the current circumstances. Orientation is the moment where prior knowledge is evaluated and new information are embraced, both considering the 
observed context and feasibility. The Decision is the essential stage where the innovation is flourishing. A great number of hypotheses are generated and feedback into what is learnt in the observation and orientation stages. The hypothesis has to be testable to sustain the cause-effect notion that the theory will be favourable and desirable. Having established how the OODA Loop is useful in our study and which the steps in the loop we want to change, we will review literature to define key mechanisms.

\section{EFFECT OF DESIGNERLY THINKING}

The discussed literature informs us that purely basing decision-making on convergent thinking (which involves applying criteria, standards, and logics based on their prior knowledge and experience to form judgement), does not necessarily lead to the best decision outcomes. The combination of convergent thinking with logics that are directed to something 'new', i.e. future developments, future extensions on an idea or simply applying creative thought of some description, can lead to significantly better decision outcomes.

In the following, we present a review of key literature on the mechanisms for divergent thinking, abductive reasoning, lateral thinking and analogising in decision-making. We used Dresch et al. (2015)'s criteria to analyse the literature, which was sourced from areas like design, entrepreneurship, engineering, business, management and cognitive psychology, based on keywords such as: divergent thinking, innovation, abductive reasoning, future-oriented thinking, future thinking, decision-making, extreme uncertainties, lateral thinking, inductive reasoning, deductive reasoning, strategy, and radical innovation. In the following, we succinctly describe what each identified author has focused on and the effect that they were trying to achieve, in order to influence individual decision-making. Table 1 then summarises the findings.

- Berg (2016) experiments with conditions of creative forecasting in different groups with different manipulations before the decision-making task took place. The setup is a classical between groups study. For the test group, the manipulation was to make some participants spend time generating ideas (i.e. divergent thinking) for new products before turning to the decision-making task (convergent thinking), in which they had to select innovation ideas for further development. For the control group, no divergent thinking task was required prior to the decision-making task. The intention was to improve accuracy in creative forecasting through divergent thinking. This is based on the theory that creative forecasting is likely to enhance ability in selecting innovative ideas with merits that will only be a reality in a (distant) future (Mumford et al., 2002; Byrne et al., 2010). The combination of divergent thinking, involving association of novel ideas with present conditions (Guilford, 1967), and convergent thinking applies criteria of prior knowledge (Cropley, 2006) leading to a more conscientious decision-making outcome.

- Dong et al. (2016) observe how deductive and abductive reasoning during design evaluation and their influence decision-making behaviour and outcomes in selecting innovation ideas for funding. Abductive reasoning was used as a manipulation in a between groups setup. The generation of abductive hypotheses is shown to help the conception of future trajectories leading to viable innovation opportunities. Then future-oriented-selection-criteria will be considered during the convergent phase. The authors want to break with pattern recognition and other decision-making biases by focusing on developing opportunity for the raw idea shown, rather than on what is proposed to the decision maker at the point of decision-making. Abductive reasoning allows decision makers to create alternative, testable hypothesis about the future potential of a given opportunity. Thereby, it allows them to think beyond what is proposed and direct their thought to future opportunity (see also Govindarajan \& Trimble, 2010).

- De Bono (1970) tries to use lateral thinking exercises to boost creativity in people. The idea behind the experiment is that by using lateral thinking, people are better at selecting alternative ideas. In his exercises, individuals are presented with problems where lateral thinking should be applied to solve it in an innovative and efficient way. Whereas, a control individual has to keep working on the problem in a linear way without extending the working boundaries. The desired effect is that by using neither logical nor linear way of reasoning, the individual will more likely generate innovative solutions and therefore improve the decision based on that open mindness. This is a way of thinking that seeks a solution to a complex problem through unorthodox methods that would normally be ignored by logical thinking. Commonly it is described as thinking 'outside-the-box' and connecting usually unrelated clues. 
- Baron (2006) focuses on how pattern recognition and "connecting the dots", in other words, merging different sources of knowledge, affects decision-making in the specific context of entrepreneurship: Using models of pattern recognition - prototype models or exemplar models to understand possible connection. Based on a literature review, Baron researches the effectiveness of these methods concluding that by using a cognitive framework as a process research, alertness and prior knowledge - it should improve opportunity recognition and the ability to act upon them which ultimately benefits the decision-making phase. In other words, generating more innovative opportunities by recognising trends, one is more likely to pick a winner. The study is based on experience-cognitive framework that are used to connect the unrelated events or trends in the world and the connectedness will potentially benefit the generation of new solution and the convergent phase (Ardichvili et al., 2003; Kirzner, 1985).

- Huang and Pearce (2015) measure early-stage entrepreneurial investment decisions (mainly angel investors) in situations of extreme uncertainties. The generation and the selection of an idea is based on a dynamic emotion-cognition which merges accurate analysis and expertise-based intuition. The first study was a group observation on how angel investors described their decision-making identifying instances of biases by retrospective sense-making and faulty memory which affect "gut feeling" decisions in the future. The second study was an experiment with a between-group setting. Groups were assigned with different business plans that were categorised with four criteria to affect the manipulation, in particular they tried to control for participants' prior experience. This showed subjects' different ways of dealing with unknowable risk in a strategic decision and the formal analysis in supporting intuition such as gut feeling (Wilson, 2002). It is found that successful angel investors are more risk-seeking and use intuition, based on inductive thinking and experience, to make their decisions (Alvarez \& Barney, 2007; Sarasvathy, 2001). This intuition or "emotional-cognitive gut feeling" requires the ability to use past experience and hypothesis about the future based on this.

- Dew et al. (2009) experiment with a given imaginary product where participants were asked to describe their decisions on whether or not to further develop them as they were making them (think-aloud), which is concurrent and not recalled back from memory (Ericsson \& Simon, 1980). The manipulation was the underlying theorisation of thinking aloud which derive its validity from the immediacy of the thoughts. Here retrospective and introspective biases were avoided. The experiment was very constrained in trying to highlight the weight of prior knowledge and logical framing. People with more experience use analogies and holistic view to make decision. Experienced decision makers use effectual logic whereas novices use predictive logic to solve the problem (Chi et al., 1982). Another consideration is the theory that expertise differs from experience which is defined as weaker indicator due to induce people making a wrong decision. Hence, in this study expert participants shown to possess stronger skills as analogical reasoning, holistic view and weighting of information to make better decisions.

- Eggers et al. (2017)'s experiments using a group web-based business simulation where participants where asked to start and run a company. Individual teams were asked to make decision to grow the company. These decisions required critical thinking skills in order to create competitive advantages for the business. Analysis of the taken decision and the relationship between creativity and critical thinking was assessed based on James and Brett (1984) four steps establishing mediation. The desired effect is to prove creativity to work as medium between critical thinking and business performance, and whether this is supported or not by a framework that may enhance efficiency of problem solving and team commitment (Sousa et al., 2014). Another important aspect in support of this theory comes from Wertz et al. (2013) who see a positive relationship between critical thinking and the collection of information, accuracy and evaluation of the former. Critical thinking is defined by Whitten and Brahmasrene (2001, p. 1) as "cognitive engine that drives problem-solving".

- Dorst (2011) theorises "IF we look at the problem situation from this viewpoint, and adopt the working principle associated with that position, THEN we will create the value we are striving for". A strong value creation (abductive reasoning) is then followed by a deductive reasoning to prove its effectiveness. Innovative solutions are a juxtaposition of working principle (How) and thing (What) that work toward a preconceived value. Abductive reasoning enhances the capability to make decision toward a value, and validate it backward (deductive reasoning) to test 
the hypothesis. The research shows similarity in strategies to support 'good' decision-making to those proposed by Dong et al. (2016).

- Dunne and Dogherty (2016)'s study is based on grounded theory-building analysis which was contended to be an abductive exercise by Strauss \& Cobin (1998). The authors run various interviews asking scientists and managers what they do, how they approach a decision, which problem they faced and which differences have been observed across projects that they have worked on. The authors identify three basic areas influencing decision-making: noise reduction, competency trap avoidance, and insights in a holistic way. A code based on Strauss \& Cobin (1998) was developed to analyse and categorise the responses. The aim of this study was to observe mental models and frameworks used to navigate through the innovation process and to arrive at a confident decision. The theory behind this research is that actors as the authors define decision makers know the effect of the decision only once it has been made. Thus, there is not a linear path to navigate the labyrinth's complexity. Indeed, the outcome is a sequence of repeated actions. One decision segues another decision. Eventually, there is a high level of complexity in the decision, and one minor change may trigger major change to the whole system (Plowman et al., 2007).

Table 1. Analysis of current literature on idea generation methodology and timing of intervention relative to decision point

\begin{tabular}{|c|c|c|c|c|}
\hline Author & $\begin{array}{c}\text { Targeted } \\
\text { manipulation }\end{array}$ & Effect & $\begin{array}{c}\text { Individual } \\
\text { or Group } \\
\text { decision }\end{array}$ & $\begin{array}{c}\text { Timing of } \\
\text { intervention } \\
\text { relative to } \\
\text { decision }\end{array}$ \\
\hline Berg 2016 & $\begin{array}{l}\text { Divergent } \\
\text { Thinking }\end{array}$ & $\begin{array}{l}\text { Combination of divergent } \\
\text { and convergent thinking }\end{array}$ & Group & Before \\
\hline $\begin{array}{l}\text { Dong et al., } \\
2016\end{array}$ & $\begin{array}{l}\text { Abductive } \\
\text { Reasoning }\end{array}$ & $\begin{array}{l}\text { Breaking through the pattern } \\
\text { recognition and similar } \\
\text { decision-making biases }\end{array}$ & Individual & During \\
\hline $\begin{array}{l}\text { De Bono } \\
1970\end{array}$ & Lateral Thinking & $\begin{array}{l}\text { Fostering out-of-the-box } \\
\text { thinking }\end{array}$ & Individual & During \\
\hline Baron 2006 & $\begin{array}{l}\text { "Connecting the } \\
\text { Dots" }\end{array}$ & $\begin{array}{l}\text { Recognition of a pattern and } \\
\text { use of cognitive framework } \\
\text { to connect the dots }\end{array}$ & Individual & Before \\
\hline $\begin{array}{l}\text { Huang and } \\
\text { Pearce } 2015\end{array}$ & $\begin{array}{l}\text { "Emotional- } \\
\text { Cognitive" }\end{array}$ & $\begin{array}{l}\text { Analysis and intuition in } \\
\text { making the decision }\end{array}$ & Individual & Before and After \\
\hline $\begin{array}{l}\text { Dew et al., } \\
2009\end{array}$ & Effectual Logic & $\begin{array}{l}\text { Using framework for the } \\
\text { decision-making }\end{array}$ & Group & $\begin{array}{r}\text { Before and } \\
\text { During } \\
\end{array}$ \\
\hline $\begin{array}{l}\text { Eggers et al., } \\
2017\end{array}$ & Critical Thinking & $\begin{array}{l}\text { Analysis and evaluation of } \\
\text { course of action }\end{array}$ & Group & During \\
\hline Dorst 2011 & Design Reasoning & Creation of Value first & Individual & During \\
\hline $\begin{array}{l}\text { Dunne and } \\
\text { Dougherty } \\
2016\end{array}$ & $\begin{array}{l}\text { "Labyrinth } \\
\text { Reasoning" }\end{array}$ & $\begin{array}{l}\text { Mental model to navigate } \\
\text { through the innovation } \\
\text { process }\end{array}$ & Individual & During \\
\hline
\end{tabular}

By analysing these studies, an overlap is visible in how the generation of an idea should be stimulated from alternative directions which constitute divergent thinking, lateral thinking and abductive reasoning (see De Bono, Berg and Dong et al.), which is ultimately succeeded by a convergent phase. The latter can be supported by (experience-based) induction and pattern recognition (see Baron, 2006 and Dew et al., 2009) to select the most likely winners out of a given set of future-oriented hypotheses. Another important overlap to consider is the ability to transfer knowledge in the moment of generation and selection. All these mechanisms are playing an important role in making a decision which is future-oriented. Hence, we will incorporate these effects in the OODA Loop in order to advance the framework. We see a benefit in introducing abductive reasoning, divergent thinking and lateral thinking due their conceptual thinking of diversifying options and see further and beyond of their existing form. The reason for incorporating pattern recognition and knowledge transfer is because both support the decision phase, whether widening the scope and possibilities of that specific decision, or seeing connection with different sources of information. 


\section{LINKING OODA WITH DIVENGENT AND FUTURE THINKING MECHANISMS}

In the future, decision makers will have to make more and more decisions in scenarios characterised by extreme uncertainty. The following framework intends to help decision makers dealing with unknown situations and make the best decisions with the limited information that is available at the time. In this section, we will link the key findings from the systematic review and embed them into the OODA Loop within the Decide phase in an attempt to make decisions more accurate and more effective. For this study, Observe, Orient and Act are kept as the original framework present them since we believe they are very strong in their purpose and the Decide part could highly benefit from the divergent thinking mechanism validated in the literature review.

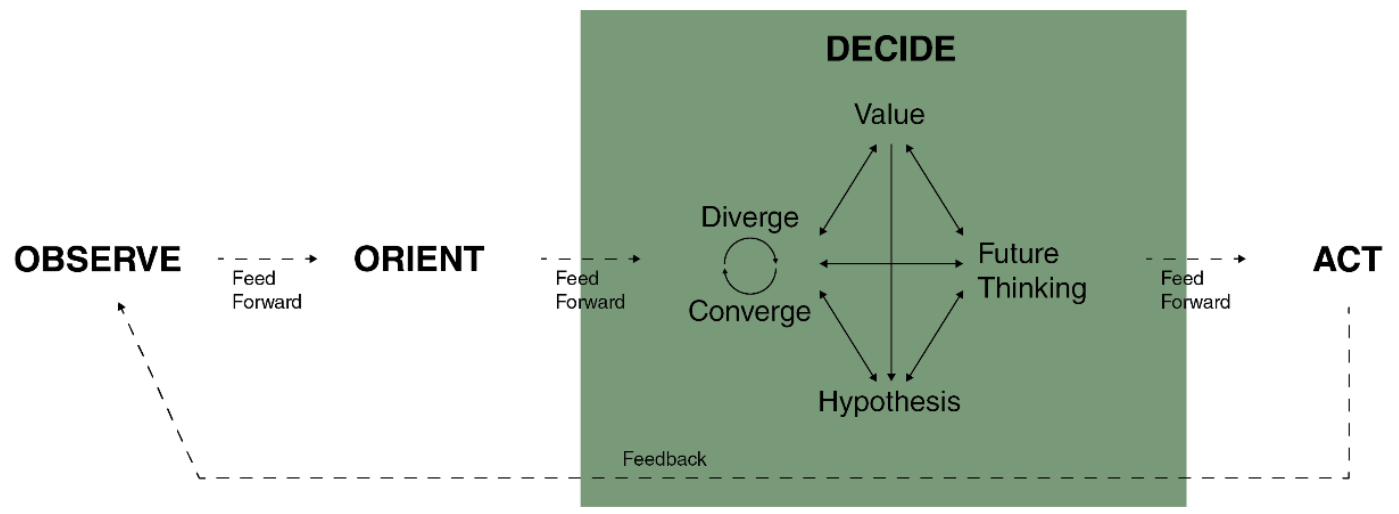

Figure 2. Advanced OODA loop

The discussed mechanisms can be integrated into the "Decide" phase of the OODA Loop. Here hypotheses are generated and a selection is made that guides a course of action. The overlapping divergent and convergent mechanism may have impact in helping the decision maker to better envision possible solutions, generate future-oriented alternatives converging on the 'best' opportunity. This part is even stronger if value described by Dorst (2011) is the starting point of the decision. In this way it will be simpler to concentrate on selecting a solution that is more likely to meet such value. In doing so, a valid support may come from pattern recognition and knowledge transfer which might further endure in decision-making and eventually transform the meaning of the outcomes. The decide phase is more suitable for the introduction of these mechanisms because it comes after two important aspects: observation and orientation. In these phases, research is conducted to collect enough knowledge to move to the decision phase. Here important information regarding context, stakeholders, markets, technology and the like are gained and then aggregated toward the company's preferable ultimate intention which is to make radical innovation and be competitive in the market. In following these steps, the idea of futureoriented thinking can be effectively applied in the advanced OODA Loop to the best possible decisions in a specific situation. Built into the original OODA Loop framework, the "decide divergently" part is about starting from the value that the organization wants to achieve. From here a hypothesis generation step is required to divergently think toward meeting the desired. Hypotheses then are checked against future thinking mechanism where the idea should be able to generate answers to the question "what might be?". The divergent/convergent loop, the future thinking and the hypothesis generation are constantly grounded against the desired value (See Figure 2). Through this combination of decisionmaking strategies, the OODA Loop combined with future-oriented thinking (see abductive reasoning Dong et al., 2016) can be a powerful tool to make decisions under extreme uncertainty.

In the future, we will research on how to verify our argument and improve its effectiveness by testing it in real environment. That said, these steps are overlapped with what the various authors (see Table 1) writing about designerly thinking and the likelihood effect those have. Indeed, complex innovation is full of challenges that require distilling a large amount of information and face uncountable unknowns. Dong's research investigates the potential to apply abductive reasoning to select novel innovation and how non-incremental innovation is novel in its essence and capable to change meanings. Abductive thinking is backed up by research as a way of managing complex product innovation. In doing so, new knowledge is required and therefore new insights are produced in order to reach the value that previously 
has been set as a target (Dorst, 2011). Similarly, Dunne and Dougherty (2016) argue that people are able to generate and seize hypothesis in order to make a closer sense of actual facts.

Another aspect that stood out from our analysis is the interconnectivity of various disciplines. In other words, how successful a multidisciplinary project outcome is likely to be. We can see how Baron (2006), De Bono (1970), Dunne and Dougherty (2016), Dong et al. (2016) and Dorst (2011) strongly believe in the organisation's capability to inject a wide and broad culture of open thinking and support decisions where ideas are interdisciplinary. Recalling Bauchanan (1992) and the concept of wicked problems which hold a high degree of complexity, divergent thinking, changing of meaning and multidisciplinary are ingredients to come close in solving complex problems. The latter is encompassed with unpredictable interactions of unknown cause-effects relationships (Dunne \& Dougherty, 2016). In other words, a slight change in $\mathrm{X}$ can drastically shape the result in Y. One underlying factor is that reasoning is the result of iterative cycle of formulation and evaluation (Magnini, 2001). Thus, based on the analysis we can see how the combination of divergent with convergent thinking can help decision-making in converging scenarios.

During our systematic analysis, we observed how a number of the reviewed scholars highlight that intuition honed by prior knowledge has a strong effectiveness in decision-making resulting in more appropriate decision. Mainly when the ability of making decisions is required in a fast-paced and transforming environment (Ambady and Rosenthal, 1992; Gigerezer, 2007; Huang and Pearce, 2015) which is seen as a fundamental dynamic capability of a company. On the other hand, intuition which is often attributed to a certain degree of experience and is used in case of low information availability can likely be biased and consequently may lead to predictable errors (Huang \& Pearce, 2015; Macmillan et al., 1987; Martens et al., 2007). Studies by Moreau, Lehmann and Markman (2001) and Dailey and Mumford (2006) confirm that prior knowledge can negatively affect the selection of new ideas. It can undervalue or overvalue ideas and fall into "false negatives" or "false positives" (Berg, 2016). This then begs questions, "who is the advanced OODA Loop for?", "who should be involved in making such decisions?", "what combinations of knowledge and backgrounds might be most effective?" and "what is the role of prior knowledge in general?". This will be the focus of future research.

Advancing OODA Loop with the mechanisms mentioned above - divergent and convergent thinking, value first, future thinking, pattern recognition and knowledge transfer - is expected to have positive effects and that it could provide decision makers with a suitable framework to deliberately use this more divergent, future-oriented thinking as part of their selection process. Ideally, this will then lead to better decision-making performance.

\section{CONCLUSION}

In this paper, we reviewed key literature on designerly thinking and how it can guide strategic decision-making under conditions of extreme uncertainties. We researched how divergent thinking and abductive thinking in combination with convergent thinking can have a positive effect on selecting innovation opportunities. Our aim was to integrate the mechanisms highlighted by different authors with the so-called OODA Loop, which was originally designed for air-to-air combat and is now permeating into business environments to support fast-paced strategic decision-making under uncertainty. By studying the literature, we observed overlaps in the proposed designerly ways of thinking, continuous divergent and convergent thinking, value first, pattern recognition and knowledge transfer. Based on this observation we then propose an expansion of the OODA Loop as per advancing the framework by implementing in the Decide phase the aforementioned future-oriented mechanisms. Future research targets testing the advanced framework and iteration subsequently to refine it.

\section{REFERENCES}

Alvarez, S.A. and Barney, J.B. (2007), "Discovery and creation: Alternative theories of entrepreneurial action", Strategic Entrepreneurship Journal, Vol. 1, pp. 11-26.

Ambady, N. and Rosenthal R. (1992), "Thin slices of expressive behavior as predictors of interpersonal consequences: A meta-analysis", Psychological Bulletin, Vol. 111, pp. 256-274.

Ardichvili, A., Cardozo, R. and Ray, S. (2003), "A theory of entrepreneurial opportunity identification and development”, Journal of Business Venturing, Vol. 18, pp. 105-123.

Assink, M. (2006), "Inhibitors of disruptive innovation capability: a conceptual model”, European Journal of Innovation Management, Vol. 9, pp. 215-233. http://dx.doi.org/10.1108/14601060610663587. 
Baron, R.A. (2006), "Opportunity Recognition as Pattern Recognition: How Entrepreneurs "Connect the Dots" to Identify New Business Opportunities”, The Academy of Management Perspectives, Vol. 20 No. 1, pp. 104-119. http://dx.doi.org/10.5465/AMP.2006.19873412.

Berg, J.M. (2016), "Balancing on the Creative Highwire: Forecasting the Success of Novel Ideas in Organizations", Administrative Science Quarterly, Vol. 61 No. 3, pp. 433-468. http://dx.doi.org/10.1177/0001839216642211.

Bonchek, M. and Fussell, C. (2013), "Decision-making, Top Gun Style”, Harvard Business Review, viewed 12 September 2018, <https://hbr.org/2013/09/decision-making-top-gun-style>.

Brown, T. (2009), Change by design: How design thinking transforms organizations and inspires innovation, HarperCollins, New York, NY.

Buchanan, R. (1992), “Wicked Problems in Design Thinking”, Design Issues, Vol. 8 No. 2, pp. 5-21. http://dx.doi.org/10.2307/1511637.

Byrne, C.L., Shipman, A.S. and Mumford, M.D. (2010), “The effects of forecasting on creative problemsolving: An experimental study”, Creativity Research Journal, Vol. 22, pp. 119-138.

Carlgren, L., Elmquist, M. and Rauth, I. (2016), "The Challenges of Using Design Thinking in Industry Experiences from Five Large Firms”, Creativity and Innovation Management, Vol. 25 No. 3, pp. 344-362. http://dx.doi.org/doi:10.1111/caim.12176.

Chi, M.T.H., Glaser, R. and Rees, E. (1982), Expertise in problem solving. In: Sternberg, R. J. (Ed.), Advances in the Psychology of Human Intelligence. Erlbaum, Hillsdale, NJ.

Cropley, A. (2006), "In praise of convergent thinking”, Creativity Research Journal, Vol. 18, pp. 391-404.

Cross, N. (2011), Design thinking: understanding how designers think and work, Berg Publishers, Oxford.

Csikszentmihalyi, M. (1999), "Implications of a systems perspective for the study of creativity",.Handbook of creativity. Cambridge University Press, New York, NY, US.

De Bono, E. (1970), Lateral thinking: creativity step by step, Harper and Row, New York.

Dailey, L. and Mumford, M.D. (2006), "Evaluative Aspects of Creative Thought: Errors in Appraising the Implications of New Ideas”, Creativity Research Journal, Vol. 18 No. 3, pp. 385-390. http://dx.doi.org/10.1207/s15326934crj1803_11.

Dew, N., Read, S., Sarasvathy, S.D. and Wiltbank, R. (2009), "Effectual versus predictive logics in entrepreneurial decision-making: Differences between experts and novices", Journal of Business Venturing, Vol. 24 No.4, pp. 287-309. https://doi.org/10.1016/j.jbusvent.2008.02.002.

Diebold, F.X., Doherty, N.A. and Herring, R.J. (2010), The Known, the Unknown, and the Unknowable in Financial Risk Management Measurement and Theory Advancing Practice, Princeton University Press, Princetown, New Jersey, United States.

Dong, A., Garbuio, M. and Lovallo, D. (2016), “Generative sensing in design evaluation”, Design Studies, Vol. 45, pp. 68-91. https://doi.org/10.1016/j.destud.2016.01.003.

Dorst, K. (2011), “The core of 'design thinking' and its application”, Design Studies, Vol. 32 No. 6, pp. 521532. http://dx.doi.org/doi.org/10.1016/j.destud.2011.07.006.

Dresch A., Lacerda D.P. and Antunes J.A.V. (2015), "Design Science Research”, In: Dresch A, Lacerda DP, Antunes Jr JAV (eds) Design Science Research. Springer International Publishing, pp. 67-102.

Dunne, D.D. and Dougherty, D. (2015), "Abductive Reasoning: How Innovators Navigate in the Labyrinth of Complex Product Innovation”, Organization Studies, Vol. 37 No. 2, pp. 131-159. http://dx.doi.org/10.1177/0170840615604501.

Eggers, F., Lovelace, K.J. and Kraft, F. (2017), "Fostering creativity through critical thinking: The case of business start-up simulations”, Creativity and Innovation Management, Vol. 26 No. 3, pp. 266-276. http://dx.doi.org/doi:10.1111/caim.12225.

Enck, R.E. (2012), “The OODA Loop”, Home Health Care Management and Practice, Vol. 24 No. 3, pp. 123124 http://dx.doi.org/10.1177/1084822312439314.

Ensici, A., Bayazit, N., Badke-Schaub, P. and Lauche, K. (2008), "Decision-making in design teams: analysis of used and rejected decisions", International Design Conference - Design 2008. Dubrovnik - Croatia, May 19-22.

Ericsson, K.A. and Simon, H.A. (1980), "Verbal reports as data", Psychological Review, Vol. 87 No. 3, pp. $215-251$.

Gigerenzer, G. (2007), Gut Feelings: The Intelligence of the Unconscious, Viking, New York.

Govindarajan, V. and Trimble, C. (2010), The Other Side of Innovation: Solving the Execution Challenge, Harvard Business School Publishing, Cambridge, Massachusetts, United States.

Guilford, J.P. (1967), The Nature of Human Intelligence. McGraw-Hill, New York.

Huang, L. and Pearce, J.L. (2015), "Managing the Unknowable: The Effectiveness of Early-stage Investor Gut Feel in Entrepreneurial Investment Decisions”, Administrative Science Quarterly, Vol. 60 No. 4, pp. 634670. http://dx.doi.org/10.1177/0001839215597270.

James, L.R. and Brett, J.M. (1984), "Mediators, moderators, and tests for mediation”, Journal of Applied Psychology, Vol. 69, pp. 307-321.

Kelley, T. (2005), The Ten Faces of Innovation. Random House, New York, New York, United States.

Kirzner, I.M. (1985), Discovery and the capitalist process. University of Chicago Press, Chicago, United States. 
Kleinsmann, M., Valkenburg, R. and Sluijs, J. (2017), “Capturing the Value of Design Thinking in Different Innovation Practices", International Journal of Design, Vol. 11 No. 2.

Kotina, E., Prendeville, S. and Koria, M. (2017), "Using Design Thinking to improve Strategic Decisions during Collaborative Sensemaking", DMA 2017. Hong Kong.

Landoni, P., Dell'Era, C., Ferraloro, G., Peradotto, M., Karlsson, H. and Verganti, R. (2016), “Design Contribution to the Competitive Performance of SMEs: The Role of Design Innovation Capabilities", Creativity and Innovation Management, Vol. 25 No. 4, pp. 484-499. http://dx.doi.org/doi:10.1111/caim.12165.

Macmillan, I.C., Zemann, L. and Subbanarasimha, P. N. (1987), "Criteria distinguishing successful from unsuccessful ventures in the venture screening process", Journal of Business Venturing, Vol. 2 No. 2, pp. 123-137. https://doi.org/10.1016/0883-9026(87)90003-6.

Magnini, L. (2001), Abduction, reason, and science: Processes of discovery and explanation, Kluwer Academic Publishers, Dordrecht, Netherlands. doi:10.1007/978-1-4419-8562-0.

Maier, H.R., Guillaume, J.H.A., Van Delden, H., Riddell, G.A., Haasnoot, M. and Kwakkel, J.H. (2016), “An uncertain future, deep uncertainty, scenarios, robustness and adaptation: How do they fit together?" Environmental Modelling and Software, Vol. 81, pp. 154-164. https://doi.org/10.1016/j.envsoft.2016.03.014.

Martens, M.L., Jennings, J.E. and Jennings, P.D. (2007), "Do the stories they tell get them the money they need? The role of entrepreneurial narratives in resource acquisition”, Academy of Management Journal, Vol. 50, pp. 1107-1132.

Mason, R.O. and Mitroff, I.I. (1981), Challenging Strategic Planning Assumptions: Theory, Cases and Techniques. Wiley, New York, New York, United States.

Mckenzie, J., Van Winkelen, C. and Grewal, S. (2011), "Developing organisational decision-making capability: a knowledge manager's guide”, Journal of Knowledge Management, Vol. 15 No. 3, pp. 403-421. http://dx.doi.org/doi:10.1108/13673271111137402.

Mintzberg, H., Raisinghani, D. and Théoret, A. (1976), "The Structure of "Unstructured” Decision Processes", Administrative Science Quarterly, Vol. 21 No. 2, pp. 246-275. http://dx.doi.org/10.2307/2392045.

Moreau, C.P., Lehmann, D.R. and Markman A.B. (2001), "Entrenched knowledge structures and consumer response to new products", Journal of Marketing Research, Vol. 38, pp. 14-29.

Mumford, M.D., Lonergan, D.C. and Scott, G. (2002), "Evaluating creative ideas: Processes, standards, and context”, Inquiry: Critical Thinking Across the Disciplines, Vol. 22, pp. 21-30.

Plowman, D., Baker, T., Beck, M., Kulkarni, S. and Solansky, D. (2007), "Radical change accidentally: The emergence and amplification of small change", Academy of Management Journal, Vol. 50, pp. 515-543

Sarasvathy, S.D. (2001), "Causation and Effectuation: Toward a Theoretical Shift from Economic Inevitability to Entrepreneurial Contingency", The Academy of Management Review, Vol. 26 No. 2, pp. 243-263. http://dx.doi.org/10.2307/259121.

Shane, S. (2009), "Why Encouraging More People to Become Entrepreneurs Is Bad Public Policy", Small Business Economics, Vol. 33 No. 2, pp. 141-149.

Sousa, F.C., Monteiro, I.P., Walton, A.P. and Pissarra, J. (2014), “Adapting creative problem solving to an organizational context: A study of its effectiveness with a student population", Creativity and Innovation Management, Vol. 23, pp. 111-120.

Strauss, A. and Corbin, J. (1998), Basics of qualitative research. Cambridge University Press, Cambridge, Massachusetts, United States.

Sustein, C.R. and Hastie, R. (2015), Wiser: getting beyond groupthink to make groups smarter. Harvard Business Review Press, Cambridge, Massachusetts, United States.

Teece, D. (2007), "Explicating dynamic capabilities: the nature and microfoundations of (sustainable) enterprise performance”, Strategic Management Journal, Vol. 28 No. 13, pp. 1319-1350. http://dx.doi.org/doi:10.1002/smj.640.

Teece, D. and Pisano, G. (1994), "The Dynamic Capabilities of Firms: an Introduction”, Industrial and Corporate Change, Vol. 3 No. 3, pp. 537-556. http://dx.doi.org/10.1093/icc/3.3.537-a.

Walker, W.E., Lempert, R.J. and Kwakkel, J.H. (2013), “Deep Uncertainty”, In: GASS, S. I. and FU, M. C. (eds.) Encyclopedia of Operations Research and Management Science. Springer US, Boston, Massachusetts, United States.

Wertz, R.E., Saragih, A., Van Epps, A., Sapp Nelson, M., Purzer, S., Fosmire, M. and Dillman, B. (2013), "Work in progress: Critical thinking and information literacy: Assessing student performance", Paper presented at the 2013 annual American Society for Engineering Education Conference and Exposition.

Whitten, D. and Brahmasrene, T. (2011), "Predictors of critical thinking skills of incoming business students", Academy of Educational Leadership Journal, Vol.15, pp. 1-13.

Wilson, T. D. (2002), Strangers to Ourselves: Discovering the Adaptive Unconscious. Harvard University Press, Cambridge, Massachusetts, United States. 